\title{
MICROSTRUCTURE AND DEFORMATION OF 57Fe17Cr25NiSi AUSTENITIC SUPER ALLOY AFTER ARC PLASMA SINTERING
}

\author{
Mohammad Dani ${ }^{*}$, Arbi Dimyati ${ }^{1}$, Parikin ${ }^{1}$, Damar Rastri Adhika ${ }^{2,3}$, Aziz Khan Jahja ${ }^{1}$, \\ Andon Insani ${ }^{1}$, Syahbuddin ${ }^{4}$, Ching An Huang ${ }^{5}$ \\ ${ }^{1}$ Center for Science and Technology of Advanced Materials, BATAN, Kawasan Puspiptek \\ Serpong, Tangerang 15314, Indonesia \\ ${ }^{2}$ Research Center for Nanosciences and Nanotechnology, Bandung Institute of Technology, Jl. Ganesha \\ 10, Bandung 40132, Indonesia \\ ${ }^{3}$ Engineering Physics Research Group, Faculty of Industrial Technology, Bandung Institute of \\ Technology, Jl. Ganesha 10, Bandung 40132, Indonesia \\ ${ }^{4}$ Department of Mechanical Engineering, Faculty of Engineering, Srengseng Sawah, Pancasila \\ University, Jagakarsa, Jakarta 12640, Indonesia \\ ${ }^{5}$ Department of Mechanical Engineering, Chang Gung University, Taoyuan, Taiwan
}

(Received: March 2019 / Revised: May 2019 / Accepted: September 2019)

\begin{abstract}
The microstructure and deformation of $57 \mathrm{Fe} 17 \mathrm{Cr} 25 \mathrm{NiSi}$ super alloy are investigated in this study. The super alloy was produced from a mixture of granular ferro-scrap, ferro chrome, ferro silicon and ferro manganese raw materials by the casting method and then sintered using arc plasma for 4 and 8 minutes. The super alloy has been proposed in nuclear as well as fossil power plant facilities, such as vessels and heat exchangers. A combination of microscopy investigations by means of X-ray diffraction and high-resolution powder diffraction, optical microscopy, scanning electron microscopy and transmission electron microscopy techniques was conducted in order to obtain detailed information about the deformation of super alloy steel and its microstructures, especially fine structures. It was found that the austenitic super alloy microstructure is composed of dendrites of $\gamma$-austenite, which are separated by a eutectic structure of $\mathrm{Fe}-\mathrm{Cr}-\mathrm{C}$ alloy. Arc plasma sintering for 4 to 8 minutes leads to a decrease in the area of the eutectic structure at the inter-dendrites and forms micro strain $\varepsilon$, from $4.60 \times 10^{-3}$ to $5.39-4.06 \times 10^{-4}$.
\end{abstract}

Keywords: APS, HRPD, SEM, TEM, X-Ray Diffraction (XRD)

\section{INTRODUCTION}

In the last decade, Indonesia has been preparing new energy plans to start on a nuclear energy option in anticipation of the country's impending energy crisis. Within this framework, the Indonesian National Nuclear Energy Agency (BATAN) is at the forefront of realizing the government's plan to utilize nuclear energy to overcome the energy problem. In this context, part of the BATAN energy master plan provides for the development of an experimental nuclear power plant with a capacity of $10 \mathrm{MW}$. The proposed subsequent BATAN nuclear reactor plant will be a High Temperature Gas Cooled Reactor (HTGR) type. Certain requirements for the structural reactor materials, such as heat-exchanger pipes and vessels, must be met; among these is that the materials should have good corrosion and creep resistance.

*Corresponding author's email: mdani@batan.go.id, Tel. +62-21-7560922, Fax. +62-21-7560926

Permalink/DOI: https://dx.doi.org/10.14716/ijtech.v10i5.2991 
Further requirements include good high-temperature response to an applied mechanical load, as well as good neutron irradiation resistance (Yvon \& Carré, 2009). Meanwhile, to support the master plan, the research group for nuclear reactor material at BATAN has successfully synthesized the 57Fe17Cr25NiSi super alloy using local materials. Such material has great potential for use in a variety of high-temperature applications (Effendi et al., 2012; Effendi \& Jahja, 2014). In this study, a new 57Fe17Cr25NiSi non-standard super alloy is produced using a new Arc Plasma Sintering (APS) method (Bandriyana et al., 2017) conducted at high temperature. APS has been developed at PSTBM-BATAN and has proven to be successful in reducing both time and energy consumption in the manufacturing process.

To develop alloys with reliable and improved mechanical and thermal properties, various methods are used by adding different elements such as $\mathrm{Nb}, \mathrm{Ti}, \mathrm{Zr}, \mathrm{V}, \mathrm{W}$, Co and Mo into the super alloy, and by the hardening of solid solutions for the matrix and hardening precipitation for both the matrix and grain boundaries. Several studies (for example, Hong et al., 2001; Geddes et al., 2010;; Fukunaga et al., 2014; Silva et al., 2017; Dani et al., 2018) have conducted heat treatment and cooling with various media to modify the microstructure of $\gamma$-austenite and the grain boundary to achieve alow density of $(\mathrm{Fe}, \mathrm{Cr})_{23} \mathrm{C}_{6}$ particles and $\mathrm{Cr}$ deflection zones. In fact, grain boundary in the austenitic super alloy may be constructed by the eutectic structures of $\mathrm{Fe}$ $\mathrm{Cr}-\mathrm{C}$ alloys consisting of $\mathrm{M}_{23} \mathrm{C}_{6}$ islands and a precipitate free zone (Choi et al., 1996); $\mathrm{M}_{23} \mathrm{C}_{6}$ particles (Kaneko et al., 2011);or just the Cr deflection zones of $\gamma$-austenite. Some continuous carbide islands and $\mathrm{Cr}$ deflection zones were still found at the boundary of inter-dendrites. The high density of carbide islands and $\mathrm{Cr}$ deflection zones at grain boundaries contributes to the decrease in creep resistance (Choi et al., 1996). Some efforts have been made to reduce this formation, but the results have been not satisfactory. In order to overcome these problems, in this study the super alloy is qualitatively improved and produced using the new technology of Arc Plasma Sintering. This technique causes the onset of an inter diffusion process among the dendrites and in general is expected to be able to modify the structure of the austenitic super alloy and the dendrite boundary area, particularly its environment. In this work, the evolution of the microstructures including the boundaries of the inter-dendrites, and the deformation of the austenitic super alloy after APS treatment, are studied. Both the XRD and the neutron High Resolution Powder Diffraction (HRPD) methods are employed to determine and confirm the formation of the austenitic phase in the alloy. In addition, the Williamson-Hall (WH) method is used to analyze the XRD FWHM parameter (Irfana et al., 2018) obtained from the Gaussian function fit to the XRD reflection intensity. From the WH changes in the grainsize, the micro strain of the sample can be observed, and the micro deformation confirmed. To assess the extent of deformation associated with the sintering time of the super alloy samples, optical microscopy $(\mathrm{OM})$, scanning electron microscopy (SEM) and transmission electron microscopy (TEM) were employed for the detailed observation of the sample's microstructures.

\section{METHODS}

\subsection{Sample Fabrication}

The super alloy was fabricated by sintering the mixture containing granular chrome steel scrap, plain carbon steel scrap, FeSi75, low-carbon FeCr65, pure nickel, FeMn, slag remover and pure aluminum at the Materials Synthesis Facility POLMAN-Bandung, using an induction furnace. The aluminum was used for degassing. The super alloy cast was then sintered using arc plasma for 4 and 8 minutes. All the fabrication processes were conducted in accordance with the SOP of industrial production. Figure 1 shows the principal design of the apparatus used. 


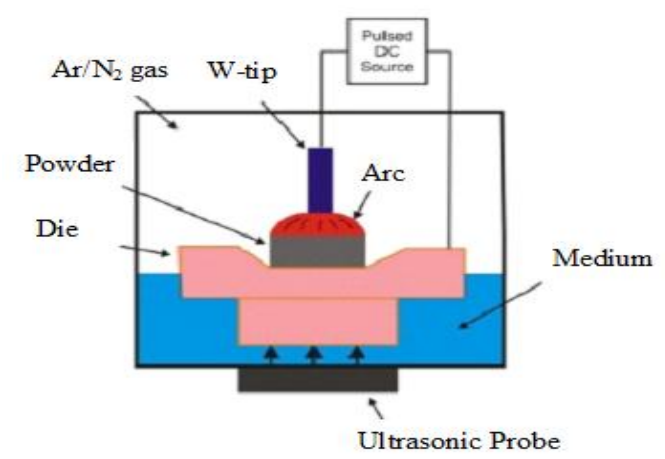

Figure 1 Schematic (Bandriyana et al., 2017) for the principal design of Arc Plasma Sintering (APS).

Small amounts of $\mathrm{FeC}$ and $\mathrm{FeCr}$ scrap were melted into an induction furnace under an $\mathrm{Ar}$ atmosphere in order to protect against oxidation. The mixture was then heated at $180 \mathrm{~kW}$ for 1 hour until the whole sample had melted. Some mixtures were slowly added into the existing melt and the final composition was obtained. FeMn, pure Ni, FeCr65 and FeSi75 were melted at $1480^{\circ} \mathrm{C}$ then poured intoa sand cast. The composition of the melt was routinely checked and controlled at a temperature of $1520^{\circ} \mathrm{C}$. The finished super alloy product consisted of $25.04 \mathrm{wt} \%$ $\mathrm{Ni}$ and $16.55 \mathrm{wt} \% \mathrm{Cr}$, providing the alloy with high strength and high corrosion resistance. It also contained a small amount of $0.504 \mathrm{wt} \% \mathrm{Mn}, 0.003 \mathrm{wt} \% \mathrm{Al}$ and $0.004 \mathrm{wt} \% \mathrm{Ti}$. The constituents of the super alloy were measured using an optical emission spectrometer (OES). The chemical compositions of the super alloy as-cast are presented in Table 1.

Table 1 Chemical composition of the $57 \mathrm{Fe} 17 \mathrm{Cr} 25 \mathrm{NiSi}$ super alloy as-cast measured by Optical Emission Spectroscopy (OES)

\begin{tabular}{cccccccccc}
\hline Elements & $\mathrm{Fe}$ & $\mathrm{Ni}$ & $\mathrm{Cr}$ & $\mathrm{Si}$ & $\mathrm{C}$ & $\mathrm{Mn}$ & $\mathrm{Al}$ & $\mathrm{Ti}$ & $\mathrm{P}$ \\
\hline \%wt. & $\mathrm{Bal}$. & 25.04 & 16.55 & 0.89 & 0.293 & 0.504 & 0.003 & 0.004 & 0.013 \\
\hline
\end{tabular}

\subsection{XRD and Neutron HRPD Measurements}

\subsubsection{Measurement}

The crystal structure of the austenitic superalloy (AS) was characterized using a PAN alytical Empyrean X-ray diffractometer with $\mathrm{Cu}$-target $(\lambda=1.5405 \AA)$, nickel filtered $\mathrm{Cu} \mathrm{K} \alpha$ radiation and a scintillation detector. Silicon powder was used as an internal standard. The neutron diffraction measurements were conducted using a DN3 high resolution powder diffractometer at the GAS Siwabessy Multipurpose Reactor at BATAN Laboratory. Neutron powder diffraction patterns were collected at room temperature for the $57 \mathrm{Fe} 17 \mathrm{Cr} 25 \mathrm{NiSi}$ super alloy. The diffraction data were collected using a $1.8221 \AA$ neutron beam in the $2 \theta$ range of 2.52 to $162^{\circ}$ at a step size of $0.05^{\circ}$. 4 to 6 hours was taken to collect the data from the neutron diffraction. The bar sample was set in an upright position on the sample table, and was partly irradiated in the neutron beam. Diffraction peak locations, estimated standard deviations for both the XRD intensity and the neutron HRPD intensity were determined by Rietveld refinements of the observed diffraction intensity data.

\subsubsection{Williamson-Hall Plots for Crystallite Size and Strain Measurements}

Since all crystals are of finite size, there is no crystal which is perfect. Therefore, any measurement of a crystal's diffraction intensity, either by X-Ray diffractometer or a neutron high resolution diffractometer, would ultimately lead to a broadening of the diffraction peaks, which in turn is also an experimental effect due to the crystal's deviation from perfection. The particle size in general differs from the crystallite size, which in this case forms the coherent diffraction domain in the sample. The fabrication process of an alloy generally introduces 
various sources of strain in the sample. Normally alloying and sintering would be the main sources of strain in the sample, along with lattice dislocation etc. From an analysis of the X-ray profile broadening, information such as crystallite size and lattice strain could be extracted (Cullity \& Stock, 2001). By considering the X-ray diffraction peak width as a function of $2 \theta$, one can easily deconvolute the broadening of the diffraction peak to obtain both the crystallite size and the (micro) strain induced in the sample, by utilizing the Williamson Hall (WH) analysis method (Suryanarayana \& Norton,1998). The WH equation is expressed as $\beta_{\mathrm{hkl}}$ $\cos \theta=(\mathrm{K} \lambda / \mathrm{D})+4 \varepsilon \sin \theta ; \beta_{\mathrm{hkl}}$ is the FWHM parameter of the XRD reflection intensity; $\mathrm{K}$ is the shape factor and is equal to $0.9 ; \lambda$ is the wavelength of the $\mathrm{X}$-ray radiation; $D$ is the crystalline size; and $\varepsilon$ is the micro strain. By plotting $\beta_{\mathrm{hk} 1} \cos \theta$ versus $4 \sin \theta$ and performing a linear regression analysis, the crystalline size $D$ and micro strain $\varepsilon$ can be obtained.

\subsection{Microstructure Observation}

The microstructure of the sample was observed through OM, SEM, and TEM. Specimens for the OM and SEM observation were prepared using the metallographical technique. They were cut from the bulk material alongside the longitudinal axis; the rough surface of the specimens was then ground with $\mathrm{SiC}$ sandpaper up to 2000 mesh grade and subsequently polished with an alumina suspension of $1 \mu \mathrm{m}$. The specimen was etched using Kalling's regent $\left(\mathrm{HCl}\right.$ and $\left.\mathrm{CuCl}_{2}\right)$ solution. For the SEM surface morphology analysis of the bulk specimen, a scanning electron microscope from Jeol JSM 6510 LA equipped with EDS Jeol was used. OM and SEM observation was performed at the Center for Science and Technology of Advanced Materials BATAN. For TEM observation, the samples should be around $100 \mathrm{~nm}$ thick in order to be electron transparent. In order to fabricate the TEM lamella specimens, focused an ion beam (FIB) FB2200 was employed. The TEM analysis was conducted using a TEM Hitachi H9500 equipped with an EDS detector from EDAX, where the TEM observation was performed at an acceleration voltage of $300 \mathrm{kV}$. Observation of the sample fabrication with FIB and HRTEM was performed at the Research Center for Nanosciences and Nanotechnology (RCNN), Bandung Institute of Technology, Indonesia.

\section{RESULTS AND DISCUSSION}

\subsection{X-ray Diffraction Analysis}

The Rietveld refinement of the X-ray- diffraction intensities of the $57 \mathrm{Fe} 17 \mathrm{Cr} 25 \mathrm{NiSi}$ super alloy is shown in Figures 2a-2c. The X-ray diffraction results confirm that the matrix of AS exhibits a FCC crystal structure with a lattice parameter of around 3.593(2) $\mathrm{A}$, with grain sizes ranging from 10.50 to $55.99 \mathrm{~nm}$. As seen in Figures $2 \mathrm{a}-2 \mathrm{c}$, the peak intensity of the (111) and (200) planes is more prominent than other peaks by increasing the sintering time from 4 to 8 minutes. Increasing the peak intensity indicates that the quality of austenite grains increases in the super alloy matrix sintered for 4 to 8 minutes. To obtain parameters used in the lattice deformation analysis, each diffraction reflection of the as-cast and APS samples was analyzed using the regression analysis method via the Gaussian function. The Gaussian fitting function here, $f(x)=$ $a \exp \left(-(x-b)^{2} / 2 c^{2}\right)$, is the fitting result: $a$ is the fitted maximum intensity of the reflection peak; $b$ is the $2 \theta^{\circ}$ position of the reflection peak; and $c$ is the $F W H M$ or the $2 \theta_{\mathrm{hkl}}$.

In Figures 3a-3c, the Gaussian fits to the (111) reflection peak for the austenite superalloy ascast after being treated for 4 and 8 minutes are shown. From Gaussian fitting to the reflection peaks, the angular peak position $2 \theta_{0}$, the FWHM parameter of the reflection peak and the magnitude of the reflection intensity are obtained and presented in Table 2. Table 3 shows that the interplanar distances decrease in line with an increase in the APS time, so the deformation of the super alloy occurs at the micro strain scale. The Williamson-Hall (WH) method can track micro strain magnitudes. 

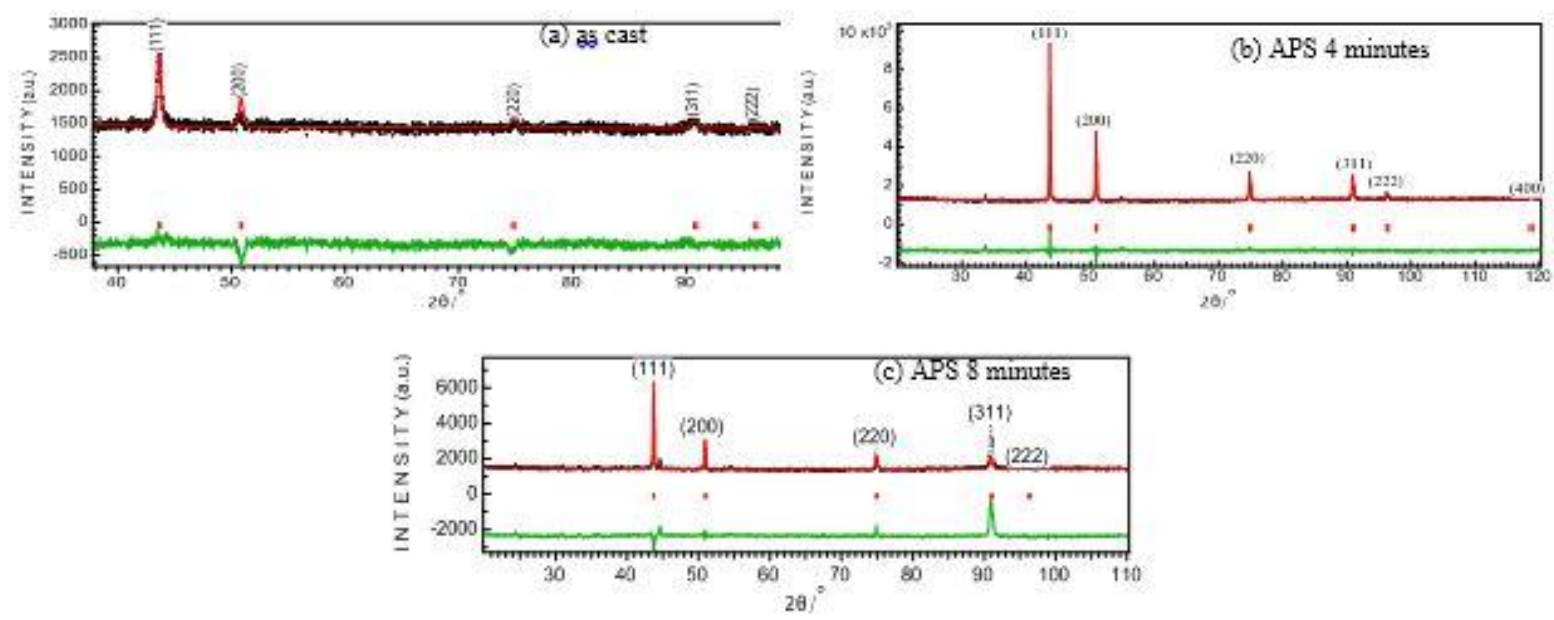

Figure 2 X-Ray Diffraction Pattern and Rietveld refinement results of the 57Fe17Cr25NiSi super alloy (a) as cast and (b-c) after arc plasma sintering for 4 and 8 minutes respectively

The method has become accepted as one of the more rigorous and widely used ways of separating the effects of size and strain (Sapna et al., 2017). The treatment behind the method is quite complex and involves expressing the peak intensity in terms of a Fourier sum, which has distinct mathematical advantages (half of the terms - the sine components - turn out to be negligible, and deconvolution is conveniently handled in Fourier space). The Williamson-Hall plot $\beta \cos \theta$ vs. $4 \sin \theta$ are presented in Figure 4 , while the changes in the interplanar distance $d_{\mathrm{hkl}}$ are presented in Table 3 .

Table 2 Results of Gaussian regression fitting to the XRD reflection peaks for the $57 \mathrm{Fe} 17 \mathrm{Cr} 25 \mathrm{NiSi}$ super alloy

\begin{tabular}{|c|c|c|c|c|c|c|c|c|c|}
\hline \multicolumn{4}{|c|}{$\overline{\text { As-cast }}$} & \multicolumn{3}{|c|}{ 4-minute APS } & \multicolumn{3}{|c|}{ 8-minuteAPS } \\
\hline$(h k l)$ & $2 \theta_{0}$ & $\begin{array}{c}\text { FWHM/ } \\
\beta\left(^{\circ}\right)\end{array}$ & Io & $2 \theta_{\mathrm{o}}$ & $\begin{array}{c}\text { FWHM/ } \\
\beta\left(^{\circ}\right)\end{array}$ & Io & $2 \theta_{\mathrm{o}}$ & $\begin{array}{c}\text { FWHM/ } \\
\beta\left(^{\circ}\right)\end{array}$ & Io \\
\hline$\overline{(111)}$ & $43.64(5)$ & $0.221(9)$ & $\overline{1054}$ & $43.69(1)$ & $0.109(2)$ & 7344 & $43.702(1)$ & $0.1026(2)$ & 3364 \\
\hline (200) & $50.75(4)$ & $0.376(4)$ & 214 & $50.899(9)$ & $0.141(2)$ & 2451 & $50.92(1)$ & $0.1469(4)$ & 1446 \\
\hline (220) & $74.71(5)$ & $0.016(6)$ & 91.82 & 74.82(1) & $0.071(2)$ & 938 & $74.875(1)$ & $0.05966(1)$ & 895 \\
\hline (311) & - & - & - & $90.868(7)$ & $0.095(1)$ & 637 & 90.94(1) & $0.10773(2)$ & 1231 \\
\hline (222) & - & - & - & $96.169(1)$ & $0.12(2)$ & 369 & $96.28(3)$ & $0.1377(2)$ & 212 \\
\hline
\end{tabular}
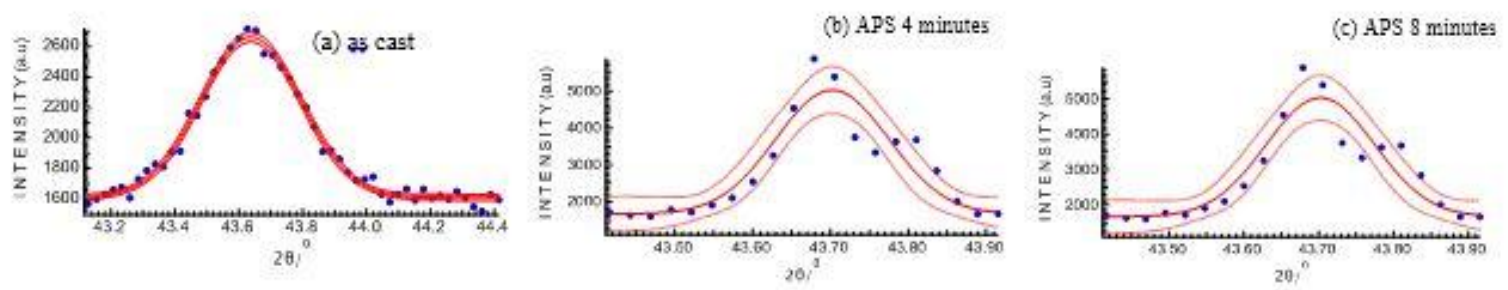

Figure 3 Gaussian fitto the (111) reflection peak of the 57Fe17Cr25NiSi super alloy(a) as cast and (b-c) after arc plasma sintering for 4 and 8 minutes, respectively

From the Williamson-Hall plots presented in Figures $4 a-4 c$, both the crystalline size D and the micro strain $\varepsilon$ can be calculated from the intercept and the slope of the Williamson-Hall equation, as presented in Table 4. It can be concluded that the crystalline size $D$ has increased and the micro strain $\varepsilon$ has decreased in line with the duration of the APS treatment. 
Table 3 Values of interplanar distance, $d_{\mathrm{hkl}}$, for the $57 \mathrm{Fe} 17 \mathrm{Cr} 25 \mathrm{NiSi}$ super alloy as-cast, after arc plasma sintering for 4 and 8 minutes

\begin{tabular}{lccccc}
\hline \multicolumn{1}{c}{ Sample } & $d_{111}(\AA)$ & $d_{200}(\AA)$ & $d_{220}(\AA)$ & $d_{311}(\AA)$ & $d_{222}(\AA)$ \\
\hline As-cast & 2.072474 & 1.797427 & 1.269497 & - & - \\
4-minute APS & 2.070083 & 1.792515 & 1.267903 & 1.081165 & 1.035123 \\
8-minute APS & 2.069542 & 1.791825 & 1.267108 & 1.080496 & 1.034224 \\
\hline
\end{tabular}

Table 4 Crystalline size and micro strain for the $57 \mathrm{Fe} 17 \mathrm{Cr} 25 \mathrm{NiSi}$ super alloy as-cast, after arc plasma sintering 4 and 8 minutes

\begin{tabular}{lcc}
\hline \multicolumn{1}{c}{ Sample } & Crystalline size $D(\mathrm{~nm})$ & Micro strain $\varepsilon$ \\
\hline As-cast & 10.50 & $4.60 \times 10^{-3}$ \\
4-minutes APS & 50.55 & $5.39 \times 10^{-4}$ \\
8-minutes APS & 55.99 & $4.06 \times 10^{-4}$ \\
\hline
\end{tabular}

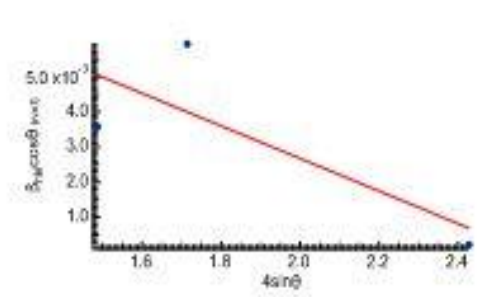

(a) as cast

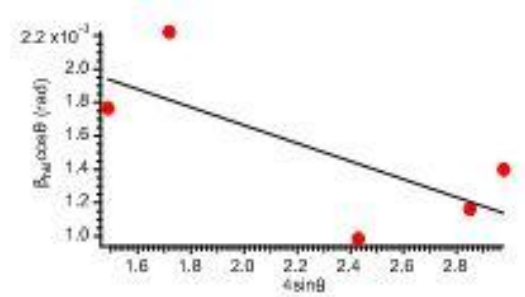

(b) APS 4 minutes

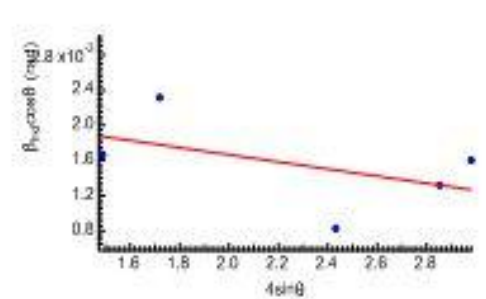

(c) APS 8 minutes

Figure 4 Williamson-Hall plot for the 57Fe17Cr25NiSi super alloy (a) as cast and (b-c)after arc plasma sintering for 4 and 8 minutes respectively.

\subsection{Neutron Diffraction Analysis}

Investigation of crystal structures using neutron diffraction techniques (HRPD) has also been conducted on super alloy ferritic steels (Parikin et al., 2018), as well as on 57Fe17Cr25NiSi super alloy. The results of the Rietveld refinement of the HRPD neutron intensity of the $57 \mathrm{Fe} 17 \mathrm{Cr} 25 \mathrm{NiSi}$ super alloy are presented in Figure 5. The results of the HRPD neutron diffraction again confirm the FCC space group symmetry of the $57 \mathrm{Fe} 17 \mathrm{Cr} 25 \mathrm{NiSi}$ super alloy, with a lattice parameter of 3.581(2) A.

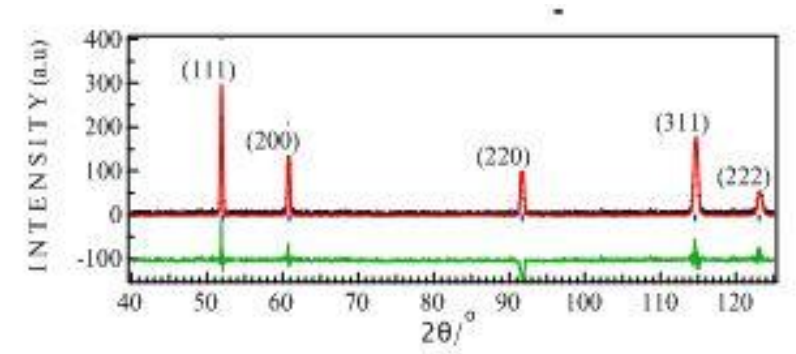

Figure 5 HRPD neutron diffraction pattern and Rietveld refinement results of the $57 \mathrm{Fe} 17 \mathrm{Cr} 25 \mathrm{NiSi}$ super alloy after arc plasma sintering for 4 minutes

\subsection{Microstructures}

As shown in Figures 6 and 7, the microstructures of the as-cast, 4 and 8 minute APS treated $57 \mathrm{Fe} 17 \mathrm{Cr} 25 \mathrm{NiSi}$ austenitic super alloy are generally composed of $\gamma$-austenite dendrites as the 
matrix and separated by an eutectic structure of Fe-Cr-C alloy. Dendrite arm spacings (DAS) for the as-cast $57 \mathrm{Fe} 17 \mathrm{Cr} 25 \mathrm{NiSi}$ austenitic super alloy are calculated to be around $223 \mu \mathrm{m}$. For the 4 the 8 minute APS 57Fe17Cr25NiSi austenitic super alloy, the spacings are around 218 and $210 \mu \mathrm{m}$, respectively. Most of the edges of the dendrite are filled with carbide particles, while the eutectic structure of $\mathrm{Fe}-\mathrm{Cr}-\mathrm{C}$ in the grain boundaries consists of discontinuous carbide islands surrounded by $\gamma$-austenite zones, which are also known as particle-free zones. This carbide island in the as-cast superalloy is part of the eutectic structure and is developed preferentially at the grain boundary (Honeycombe \& Bhadeshia, 2006).

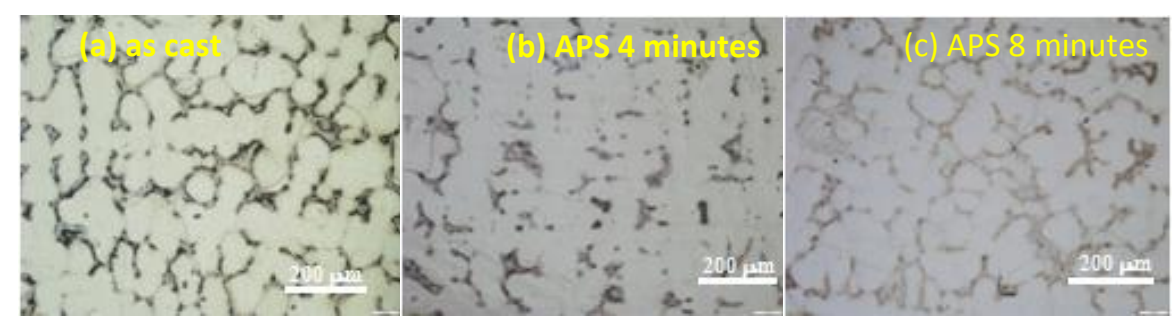

Figure 6 Optical micrographs showing the microstructures of the $57 \mathrm{Fe} 17 \mathrm{Cr} 25 \mathrm{NiSi}$ super alloy: (a) ascast, and after arc plasma sintering for times of (b) 4; and (c) 8 minutes (50x)

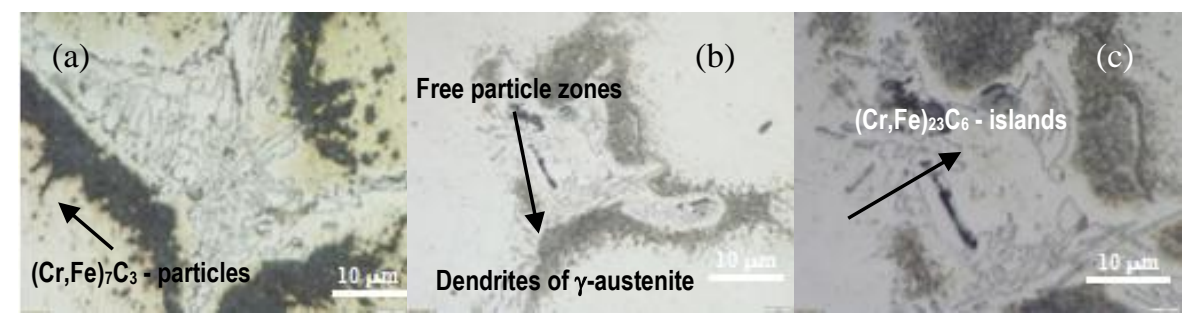

Figure 7 Optical micrographs showing the eutectic structure at the inter-dendrites of the 57Fe17Cr25NiSi super alloy: (a) as-cast, and after arc plasma sintering for times of (b) 4; and (c) 8 minutes $(1000 \times)$.

Using EDAX analysis, the composition of the island in Figure 8 is confirmed to have constituents similar to those of the $(\mathrm{Cr}, \mathrm{Fe}){ }_{23} \mathrm{C}_{6}$ carbide. The number of the eutectic structures at the inter-dendrite boundary decreases with the increased sintering time and the main part of the inter-dendrites is found in the very thin boundary, with only a few eutectic structures observed after 8 minutes APS. At the same time, in the same figure, the particles approach the $(\mathrm{Cr}, \mathrm{Fe})_{7} \mathrm{C}_{3}$ carbide composition. Such discontinuous islands and particles have also been identified as $(\mathrm{Cr}, \mathrm{Fe})_{23} \mathrm{C}_{6}$ and $(\mathrm{Cr}, \mathrm{Fe})_{7} \mathrm{C}_{3}$ in a study of $\mathrm{Fe}-\mathrm{Cr}-\mathrm{C}$ alloys (Wieczerzak et al., 2015). A similar formation is also found in the microstructure of the $57 \mathrm{Fe} 17 \mathrm{Cr} 25 \mathrm{NiSi}$ austenitic super alloy in this study.

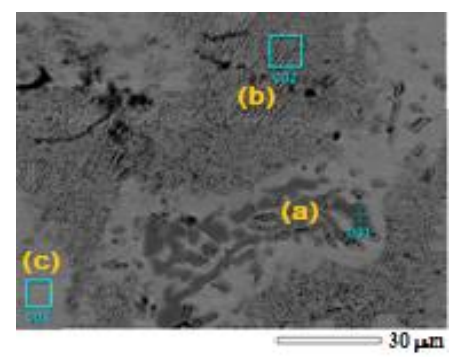

The EDS results show that the elemental compositions (\%wt.) on the precipitate spots vary as follows:

(a) Position-001: 15.9Fe, 73.64Cr, 10.45C;

(b) Position-002: 46.01Fe, 20.22 Cr, 20.75Ni, 12.29C; 0.72Si;

(c) Position-003: 54.78Fe, $18.28 \mathrm{Cr}, 25.94 \mathrm{Ni}, 1.0 \mathrm{Si}$.

Figure 8 SEM micrographs showing the microstructures of the $57 \mathrm{Fe} 17 \mathrm{Cr} 25 \mathrm{NiSi}$ super alloy as-cast in carbide: (a) islands; (b) precipitates; and (c) free precipitate zone at the grain boundary 
The development of carbide islands and particles, as well as their roundness in relation to sintering time, is presented in Figure 9. The islands of $(\mathrm{Cr}, \mathrm{Fe}){ }_{23} \mathrm{C}_{6}$ in the eutectic structure tend to be smaller after 4 and 8 minute APS. On the other hand, the carbide particles of $(\mathrm{Cr}, \mathrm{Fe})_{7} \mathrm{C}_{3}$ seem to have approximately the same size in the super alloy both before and after sintering, possibly due to the atoms in the particles having a low driving force to inter-diffuse into the matrix. Therefore, the sintering process leads to the refinement of the $(\mathrm{Cr}, \mathrm{Fe})_{23} \mathrm{C}_{6}$ carbide islands in the eutectic structure and seems to have no effect on the development of $(\mathrm{Cr}, \mathrm{Fe})_{7} \mathrm{C}_{3}$ particles at the edges of the $57 \mathrm{Fe} 17 \mathrm{Cr} 25 \mathrm{NiSi}$ austenitic superalloy matrix dendrites.

The measured interplanar distance for $d_{111}$ is $12.276 \AA$, which is around 6 times larger than the measured $d_{111}$ value obtained from the XRD measurement, which was $2.070083 \AA$. Similarly, the measured value $\left(d_{200}\right)_{\mathrm{SAED}}=14.088 \AA$ is around 8 times larger than the value obtained from the XRD measurement of $\left(d_{200}\right)_{\mathrm{XRD}}=1.792515 \AA$, and $\left(d_{220}\right)_{\mathrm{SAED}}=6.561 \AA$ is around 5 times larger than the XRD measurement value of $\left(d_{200}\right)_{\mathrm{XRD}}=1.267903 \AA$. From the SAED of the austenite matrix in Figure $8 \mathrm{a}$, the interplanar distance $\left(d_{\mathrm{hkl}}\right)$ is consistent with that for $\mathrm{Cr}_{23} \mathrm{C}_{6}$, as reported previously (Bowman et al., 1972). The measured interplanar distance $\left(d_{200}\right)_{\mathrm{SAED}}=$ $21.503 \AA$ is around 4 times larger than the $\left(d_{200}\right)=5.32 \AA$, and $\left(d_{220}\right)_{\mathrm{SAED}}=15.873 \AA$ is around 4 times larger than $\left(d_{220}\right)=3.76 \AA$. Other authors (for example, Plaut et al., 2007; Geddes et al., 2010) have reported that the $\gamma$-austenite and $(\mathrm{Cr}, \mathrm{Fe})_{23} \mathrm{C}_{6}$ island have lattice parameters of 3.565 $\AA$ and $10.50 \AA$, respectively. These values are similar to the observed interplanar distance measured from SAED, where $\left(d_{100}\right)_{\gamma}$-austenite is $3.522 \AA$ and $\left(d_{100}\right)_{(\mathrm{Cr}, \mathrm{Fe}) 23 \mathrm{C} 6}$ is $10.75 \AA$. These results show $(\mathrm{Cr}, \mathrm{Fe})_{23} \mathrm{C}_{6}$ islands in addition to the presence of $(\mathrm{Cr}, \mathrm{Fe})_{7} \mathrm{C}_{3}$ particles in the 57Fe17Cr25NiSi super alloy, as mentioned previously.
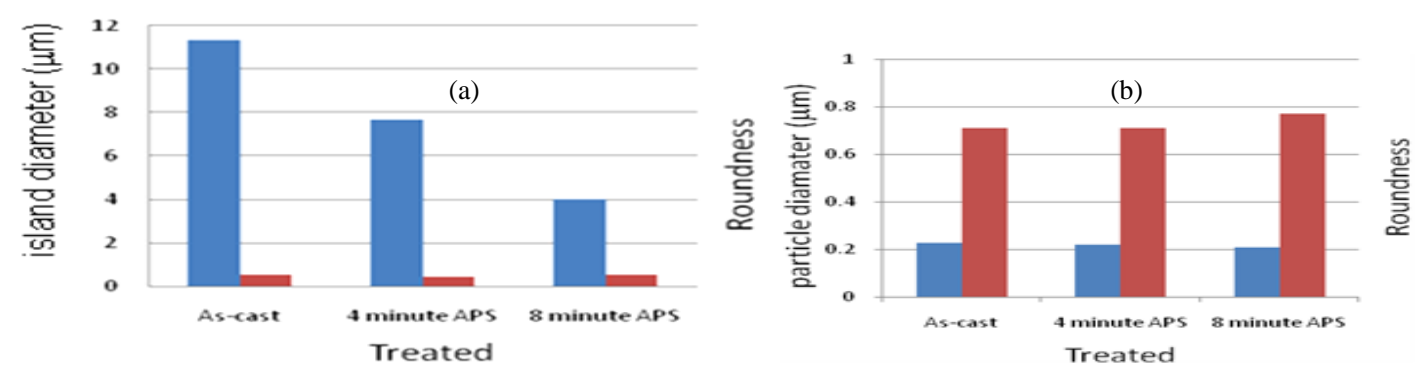

Figure 9 Histograms of: (a) carbide islands for carbide islands (blue bars); and (b) carbide particles (red bars) developed in the $57 \mathrm{Fe} 17 \mathrm{Cr} 25 \mathrm{NiSi}$ super alloy as-cast, and after 4 and 8 minutes of arc plasma sintering

\subsection{TEM Measurement Results}

Figure 10 shows the TEM images and SAED from the area of the matrix and islands in the $57 \mathrm{Fe} 17 \mathrm{Cr} 25 \mathrm{NiSi}$ super alloy. The $(\mathrm{Cr}, \mathrm{Fe})_{23} \mathrm{C}_{6}$ island were measured at $2100 \times 600 \mathrm{~nm}$. The SAED pattern of the $\gamma$-austenite matrix shows the pattern of the FCC [111] zone axis, as shown in Figure 10a, while the SAED pattern of the $(\mathrm{Cr}, \mathrm{Fe})_{23} \mathrm{C}_{6}$ island has the pattern of FCC [001], as shown in Figure 10b. From the SAED of the $\gamma$-austenite matrix at Figure 10a, the interplanar distance $\left(d_{\mathrm{hkl}}\right)$ is in accordance with the measured $d_{\mathrm{hkl}}$ obtained from the XRD measurement for the 4 minute APS prepared sample, as listed in Table 3.

The measured interplanar distance for $d_{111}$ of $12.276 \AA$ is around 6 times larger than the measured $d_{111}$ value obtained from XRD method of $2.070083 \AA$. Similarly, the measured $\left(d_{200}\right)_{\mathrm{SAED}}=14.088 \AA$ is around 8 times larger than the value obtained from the XRD method of $\left(d_{200}\right)_{\mathrm{XRD}}=1.792515 \AA$; at the same time, the value $\left(d_{220}\right)_{\mathrm{SAED}}=6.561 \AA$ is around 5 times larger than the value obtained from the XRD measurement of $\left(d_{200}\right)$ XRD $=1.267903 \AA$. From the SAED of the $\gamma$-austenite matrix as shown in Figure 10(a), the interplanar distance $\left(d_{\mathrm{hkl}}\right)$ is in 
accordance with the measured $d_{\mathrm{hkl}}$ obtained from XRD measurement of the 4 minute APS prepared sample, as listed in Table 3.
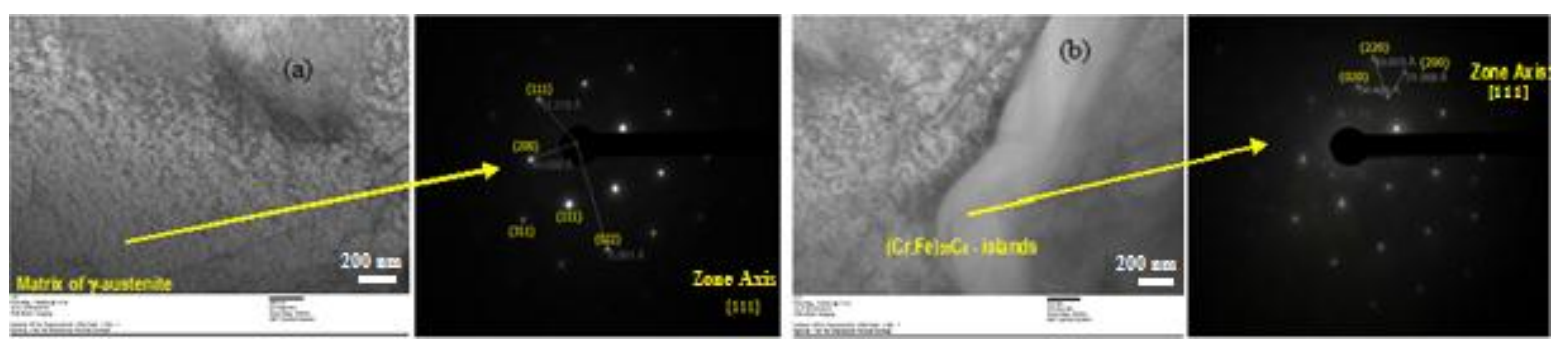

Figure 10 TEM image and SAED of: (a) matrix; and (b) $(\mathrm{Cr}, \mathrm{Fe})_{23} \mathrm{C}_{6}$ islands in the $57 \mathrm{Fe} 17 \mathrm{Cr} 25 \mathrm{NiSi}$ austenitic super alloy with 4 minute APS

\section{DISCUSSION}

The patterns of electron diffraction were successfully obtained from the matrix of $\gamma$-austenite and $(\mathrm{Fe}, \mathrm{Cr})_{23} \mathrm{C}_{6}$ islands on the $57 \mathrm{Fe} 17 \mathrm{Cr} 25 \mathrm{NiSi}$ super alloy as-cast; it was established that both regions have a face-centered cubic structure. However, the electron pattern also seems to indicate that the two regions are not coherent. In contrast, several studies (for example, Plut et al., 2007; $\mathrm{Xu}$ et al., 2018) have identified that the matrix of $\gamma$-austenite and the islands are coherent in [111] $]_{\mathrm{M} 23 \mathrm{C} 6} / /[111]_{\mathrm{M} 7 \mathrm{C} 3}$ and $\left.[110]_{\mathrm{M} 23 \mathrm{C} 6} / / 110\right]_{\mathrm{M} 7 \mathrm{C} 3}$. This difference is possible because they use different types of alloys, such as SS304 stainless steel and 100Mn13 high carbon high manganese steel. Moreover, the matrix identified in the diffraction pattern can be categorized as a $\mathrm{Cr}$ deflection zone, which is different from the $\gamma$-austenite in dendrites.

The deformation of the $57 \mathrm{Fe} 17 \mathrm{Cr} 25 \mathrm{NiSi}$ super alloy which is investigated in this study is mainly related to the micro-strain formation either in the cast or sintered samples. Sintering for 4 and 8 minutes in the samples leads to the strain being smaller than the strain in as-cast super alloy, as is evident from the W-H analysis presented in Table 4 . This condition occurs because of the effect of the sintering time. Longer sintering gives metal atoms such as $\mathrm{Fe}, \mathrm{Cr}$ and $\mathrm{Ni}$ more time to be arranged perfectly in their position in the $\gamma$-austenite crystal lattice. Moreover, the number of dissolved $(\mathrm{Cr}, \mathrm{Fe})_{23} \mathrm{C}_{6}$ carbide islands at the boundary between the dendrites during sintering is high, and is estimated to be replaced by a more stable structure in the dendrites. Thus, since the tension between the $(\mathrm{Cr}, \mathrm{Fe})_{7} \mathrm{C}_{3}$ particles, the $(\mathrm{Cr}, \mathrm{Fe})_{23} \mathrm{C}_{6}$ islands and the matrix of $\gamma$-austenite decreases, the sintering may decrease the deformation of $57 \mathrm{Fe} 17 \mathrm{Cr} 25 \mathrm{NiSi}$ super alloy which is related to the decrease in the micro strain obtained from the XRD W-H analysis.

The microstructure of $57 \mathrm{Fe} 17 \mathrm{Cr} 25 \mathrm{NiSi}$ austenitic super alloy as-cast consists of the dendrite structure of $\gamma$-austenite and eutectic structure of $\mathrm{Fe}-\mathrm{Cr}-\mathrm{C}$ alloy in the inter-dendrites. Carbide islands of $(\mathrm{Cr}, \mathrm{Fe})_{23} \mathrm{C}_{6}$ and particles of $(\mathrm{Cr}, \mathrm{Fe})_{7} \mathrm{C}_{3}$ are found in the discontinuous eutectic structure at both the grain boundary and the edges of $\gamma$-austenite dendrites, respectively. Similar formation is also observed in the $57 \mathrm{Fe} 17 \mathrm{Cr} 25 \mathrm{NiSi}$ super alloy after 4 and 8 minute APS treatment.

However, increasing the sintering time will ultimately decrease the islands' diameter, although it does not seem to have affected the changes in the $(\mathrm{Cr}, \mathrm{Fe})_{7} \mathrm{C}_{3}$ particle size. A similar case was also found in a study of an austenitic super alloy that was subjected to annealing and normalization, followed by various cooling rates (Dani et al., 2018). The decreasing number of eutectic structures during sintering, followed by an increase in the boundaries of inter-dendrites, will have a beneficial effect on the mechanical and physical properties for the $57 \mathrm{Fe} 17 \mathrm{Cr} 25 \mathrm{NiSi}$ super alloy. The decreasing number of eutectic structures will certainly reduce the number of $(\mathrm{Cr}, \mathrm{Fe})_{23} \mathrm{C}_{6}$ carbide islands. It has been reported in various articles (Choi et al., 1996; Lee et al., 
2015; Godec \& Balantic., 2016; Lee et al., 2016) that the coarse and continuous $(\mathrm{Cr}, \mathrm{Fe})_{23} \mathrm{C}_{6}$ carbide accompanied by $\mathrm{Cr}$ deflection at the boundary of inter-dendrites will be the source of deterioriation of the mechanical properties, including the strength and creep properties, beside the reduction unit's corrosion resistance.

Therefore, it is expected that the super alloy sample will be more creep resistant because sliding at the dendrite boundary without a eutectic structure is more difficult than with such a structure. Moreover, during sintering, the $\mathrm{Cr}$ content in the deflection zone becomes lower at the boundary between the dendrites. Although the $\mathrm{Cr}$ content is not very low, by decreasing this zone the corrosion resistances at the boundary between the dendrites will decrease. Thus, the strength, creep and corrosion resistances of the sample super alloy are expected to increase by a sintering process of up to 8 minutes.

\section{CONCLUSION}

Based on the extensive discussion of the effect of sintering time on the microstructure, deformation and sythesis of the $57 \mathrm{Fe} 17 \mathrm{Cr} 25 \mathrm{NiSi}$ austenitic super alloy presented above, the following conclusion can be drawn. The microstructure of 57Fe17Cr25NiSi austenitic super alloy formed either as-cast or as sintered samples consists of dendrites of $\gamma$-austenite as the matrix, separated by a eutectic structure of the Fe-Cr-C alloy. 4 to 8 minutes' sintering time decreases the number of islands of the $(\mathrm{Cr}, \mathrm{Fe})_{23} \mathrm{C}_{6}$ carbide in the eutectic structure at the grain boundary. No significant effect of sintering time was observed in the particles of the $(\mathrm{Cr}, \mathrm{Fe})_{7} \mathrm{C}_{3}$ carbide at the dendrite edges. Finally, the 4 to 8 minutes sintering time also decreases the microstrain of the $57 \mathrm{Fe} 17 \mathrm{Cr} 25 \mathrm{NiSi}$ austenitic super alloy.

\section{ACKNOWLEDGMENT}

The authors would like to express their gratitude to the Head of the Center for Science and Technology of Advanced Material for his valuable support. They would also like to thank the head of BSBM and BTBN who facilitated the research, Mr. Agus Sudjatno for assisting us with the SEM and Mr. Bambang Sugeng for the help with the XRD experiments.

\section{REFERENCES}

Bandriyana, Sujatno, A., Salam, R., Sugeng, B., Dimyati, A., 2017. High temperature Oxidation of ODS alloy with zirconia dispersions synthesized using Arc Plasma Sintering. IOP Conference Series: Materials Science and Engineering, Volume 176, pp. 1-6

Bowman, A.L., Arnold, G.P., Storms, E.K., Nereson, N.G., 1972. The Crystal Structure of Cr23C6. Acta Crystallographica Section B: Structural Crystallography and Crystal Chemistry, Volume 28(10), pp. 3102-3103

Choi, B.G., Nam, S.W., Yoon, Y.C., Kim, J.J., 1996. Characterization of the Cavity Nucleation Factor for Life Prediction under Creep-fatigue Interaction. Journal of Materials Science, Volume 31, pp. 4957-4966

Cullity, B.D., Stock, S.R., 2001. Elements of X-ray Diffraction. $3^{\text {rd }}$ edition, Prentice Hall Publications, New Delhi, India

Dani, M., Parikin, Dimyati, A., Rivai, A.K., Iskandar, R., 2018. A New Precipitation-hardened Austenitic Stainless Steel Investigated by Electron Microscopy. International Journal of Technology, Volume 9(1), pp. 328-337

Effendi, N., Jahja, A.K., Bandriana, Adi, W.A., 2012. Some Data of Second Sequence Nonstandard Austenitic Ingot A2-Type. Urania, Scientific Journal of Nuclear Fuel Cycle, Volume 18(1), pp. 48-58 
Effendi, N., Jahja, A.K., 2014. Structural Characterization and Its Physical Properties of NonStandard A1 Austenite Steel. International Journal of Materials and Mechanical Engineering, Volume 3(2), pp. 38-44

Fukunaga, T., Kaneko, K., Kawano, R., Ueda, K., Yamada, K., Nakada, N., Kikuchi, M., Barnard, J.S., Midgley, P.A., 2014. Formation of Intergranular $\mathrm{M}_{23} \mathrm{C}_{6}$ in Sensitized Type347 Stainless Steel. ISIJ International, Volume 54(1), pp. 148-152

Geddes, B., Leon, H., Huang, X., 2010. Superalloys: Alloying and Performance. ASM International, Materials Park, Ohio, USA

Godec, M., Balantic, D.A.S., 2016. Coarsening Behaviour of $\mathrm{M}_{23} \mathrm{C}_{6}$ Carbide in Creep-resistant Steel Exposed to High Temperatures. Scientific Reports, Volume (6-29734), pp. 1-7

Honeycombe, R.W.K., Bhadeshia, H.K.D.H., 2006. Steel: Microstructure and Properties. $3^{\text {rd }}$ Edition, Elsevier, New York, USA

Hong, H.U., Rho, B.S., Nam, S.W., 2001. Correlation of the $\mathrm{M}_{23} \mathrm{C}_{6}$ Precipitation Morphology with Grain Boundary Characteristic in Austenitic Stainless Steel. Materials Science and Engineering: A, Volume 318(1-2), pp. 285-292

Irfana, H., Racik K.M., Anand, S., 2018. Microstructural Evaluation of $\mathrm{CoAl}_{2} \mathrm{O}_{4} \mathrm{Nanoparticles}$ by Williamson-Hall and Size-Strain Plot Methods. Journal of Asian Ceramic Societies, Volume 6(1), pp. 54-62

Kaneko, K., Fukunaga, T., Yamada, K., Nakada, N., Kikuchi, M., Saghi, Z., Barnard, J.S., Midgley, P.A., 2011. Formation of $\mathrm{M}_{23} \mathrm{C}_{6}$-type Precipitates and Chromium-deflected Zone in Austenite Stainless Steel. Scripta Materialia, Volume 65(6), pp. 509-512

Lee, T-H., Lee, Y-J., Joo, S-H., Nersisyan, H.H., Park, K-T., Lee, J-H., 2015. Intergranular $\mathrm{M}_{23} \mathrm{C}_{6}$ Carbide Precipitation Behavior and Its Effect on Mechanical Properties of Inconel 690 Tubes. Metallurgical and Materials Transactions A, Volume 46(9), pp. 4020-4026

Lee, T-H., Suh, H-Y., Han, S-K., Noh, J-S., Lee, J-H., 2016. Effect of a Heat Treatment on the Precipitation Behaviour and Tensile Properties of Alloy 690 Steam Generator Tubers. Journal of Nuclear Materials, Volume 479, pp. 85-92

Parikin, Dani, M., Jahja, A.K., Iskandar, R., Mayer, J., 2018. Crystal Structure Investigation on the Ferritic $73 \mathrm{Fe} 24 \mathrm{Cr} 2 \mathrm{Si} 0.8 \mathrm{Mn} 0.1 \mathrm{Ni}$ Steel for Multi Purpose Structural Material Applications. International Journal of Technology, Volume 9(1), pp. 78-88

Plaut, R.L., Herrera, C., Escriba, D.M., Rios, P.R., Padilha, A.F., 2007. A Short Review on Wrought Austenitic Stainless Steels at High Temperatures: Processing, Microstructure, Properties and Performance. Materials Research, Volume 10(4), pp. 453-460

Sapna, S., Budhiraja, N., Kumar, V., Singh, S.K., 2017. X-ray Analysis of $\mathrm{NiFe}_{2} \mathrm{O}_{4}$ Nanoparticles by Williamson-Hall and Size-Strain Plot Method. Journal of Advanced Physics, Volume 6(4), pp. 1-4

Silva, F.J.G., Santos, J., Gouveia, R., 2017. Dissolution of Grain Boundary Carbides by the Effect of Solution Annealing Heat Treatment and Aging Treatment on Heat-Resistant Cast Steel KH30. Metals, Volume 7(251), pp. 1-12

Suryanarayana, C., Norton, M.G., 1998. X-ray Diffraction: A Practical Approach. Springer, New York

Wieczerzak, K., Bala, P., Stepien, M., Cios, G., Koziel, T., 2015. The Characterization of Cast Fe-Cr-C Alloy. Archives of Metallurgy and Materials, Volume 60(2), pp. 779-782

$\mathrm{Xu}, \mathrm{Z}$., Ding, Z., Liang, B., 2018. The Observation of the Structure of $\mathrm{M}_{23} \mathrm{C}_{6} / \gamma$ Coherent Interface in the 100Mn13 High Carbon High Manganese Steel. Metallurgical and Materials Transaction A, Volume 49(3), pp. 836-841

Yvon, P., Carre, F., 2009. Structural Materials Challenges for Advanced Reactor Systems. Journal of Nuclear Materials, Volume 385(2), pp. 217-222 